\title{
Beyond multidrug-resistant tuberculosis in Europe: a TBNET study
}

\author{
G. Günther, ${ }^{* \dagger}$ F. van Leth, ${ }^{\ddagger}$ N. Altet,,$^{\$ \uparrow}$ M. Dedicoat, ${ }^{\#}$ R. Duarte, ${ }^{* *+\dagger}$ G. Gualano, ${ }^{\neq \ddagger}$ H. Kunst, ${ }^{\sharp \S \S}$ \\ I. Muylle, ${ }^{\text {"17 }}$ V. Spinu, \#\# S. Tiberi, ${ }^{* * * t+t}$ P. Viiklepp, ${ }^{\neq \neq \ddagger}$ C. Lange, ${ }^{* t \S \S \S}$ for the TBNET*
}

*Division of Clinical Infectious Diseases and German Center for Infection Research Tuberculosis Unit, Research Center Borstel, Borstel, Germany; 'Department of Medicine, University of Namibia School of Medicine, Windhoek, Namibia; 'Department of Global Health, Academic Medical Center, University of Amsterdam and Amsterdam Institute for Global Health and Development, Amsterdam, The Netherlands; 'Hospital Universitari Vall d'Hebron, Barcelona, "Investigació i Recerca en Atenció Primària Jordi Gol, Barcelona, Spain; "Heart of England Foundation Trust, Birmingham, UK; **Centro Hospitalar de Vila Nova Gaia/Espinho, Vila Nova Gaia, Portugal; ${ }^{+\dagger}$ EpiUnit, Institute of Public Health; Medical School Porto University, Porto, Portugal; ${ }^{\ddagger \neq}$ L Spallanzani National Institute for

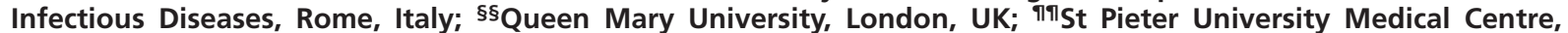
Brussels, Belgium; "\# Marius-Nasta-Institut, Bucharest, Romania; ***Azienda Ospedaliera di Valtellina e

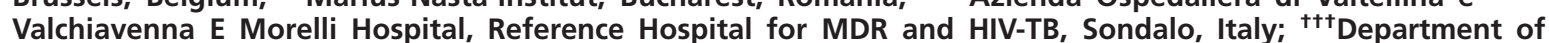
Infection, Barts Health NHS Trust, London, UK; ${ }^{\ddagger \neq \neq}$ National Institute for Health Development, Tallinn, Estonia; $\S \S \S$ Department of Medicine, Karolinska Institute, Stockholm, Sweden

S U M M A R Y

The emergence of drug-resistant tuberculosis $(\mathrm{TB})$ is a challenge to TB control in Europe. We evaluated secondline drug susceptibility testing in Mycobacterium tuberculosis isolates from patients with multidrugresistant, pre-extensively drug-resistant (pre-XDR-TB) and XDR-TB at 23 TBNET sites in 16 European countries. Over $30 \%$ of bacilli from patients with preXDR-TB showed resistance to any fluoroquinolone and almost $70 \%$ to any second-line injectable drug. Respec- tively $>90 \%$ and $>80 \%$ of the XDR-TB strains tested showed phenotypic resistance to pyrazinamide and ethambutol. Resistance to prothionamide/ethionamide was high in bacilli from pre-XDR-TB patients $(43 \%)$ and XDR-TB patients (49\%).

KEY WORDS: Europe; drug resistance; MDR-TB; TB; extensively drug-resistant tuberculosis; Tuberculosis Network European Trials
THE EMERGENCE OF DRUG-RESISTANT strains of Mycobacterium tuberculosis is a challenge to global tuberculosis (TB) control. ${ }^{1}$ Multidrug-resistant TB (MDR-TB) is defined as in vitro resistance to at least rifampicin (RMP) and isoniazid (INH). Preextensively drug-resistant TB (pre-XDR-TB) is defined as additional resistance to either a World Health Organization (WHO) Group 2 injectable drug (second-line injectables [SLIs] such as amikacin, capreomycin, kanamycin) or a WHO Group 3 fluoroquinolone (FQ). ${ }^{2}$ In XDR-TB, additional resistance to at least one drug from both WHO Groups 2 and 3 is present. ${ }^{2}$ Treatment outcomes are directly related to the level of drug resistance in $M$. tuberculosis. In a meta-analysis based on 6724 cases, treatment success was respectively $64 \%, 56 \%, 48 \%$ and $40 \%$ in MDR-TB, pre-XDR-TB (SLI resistance), pre-XDR-TB (FQ resistance) and XDR-TB patients. ${ }^{3}$ Recent surveillance data from the European Centre of Disease Prevention and Control (ECDC,
Stockholm, Sweden) showed treatment success in only $31 \%$ of MDR-TB and $19 \%$ of XDR-TB patients in Europe. ${ }^{4}$ Second-line anti-tuberculosis drug susceptibility testing (DST) is performed in only $21 \%$ of bacilli from notified MDR-TB patients in the European Region. ${ }^{4}$

We evaluated data from a prospective multinational observational cohort of MDR-/XDR-TB patients in Europe to identify patterns of second-line drug resistance in $M$. tuberculosis and risk factors for pre-XDR and XDR-TB. As part of the European Union (EU) funded TBPANNET, the present study was conducted between January 2010 and February 2014 at 23 Tuberculosis Network European Trials (TBNET; www.tb-net.org) sites specialising in the care of MDR-/XDR-TB patients in 16 European countries: 2 high TB incidence (>100 per 100000 population), 4 intermediate incidence (20-100/ $100000)$ and 10 low incidence $(<20 / 100000) .^{5}$

Correspondence to: Christoph Lange, Division of Clinical Infectious Diseases, German Center for Infection Research Clinical Tuberculosis Unit, Research Center Borstel, Parkallee 35, 23845 Borstel, Germany. Tel: (+49) 4537 188 $3320 / 1$. Fax: (+49) 4537188 3130. e-mail: clange@fz-borstel.de

Article submitted 27 March 2015. Final version accepted 2 July 2015. 
Table 1 Resistance to first- and second-line anti-tuberculosis drugs in MDR-, pre-XDR- and XDR-TB patients at 23 Tuberculosis Network European Trial sites in 16 countries in Europe

\begin{tabular}{|c|c|c|c|c|c|c|}
\hline \multirow[b]{2}{*}{ Drug } & \multicolumn{2}{|c|}{ MDR-TB $(n=258)$} & \multicolumn{2}{|c|}{ Pre-XDR-TB $(n=89)$} & \multicolumn{2}{|c|}{ XDR-TB $(n=33)$} \\
\hline & $\begin{array}{c}\text { Total tested } \\
n(\%)\end{array}$ & $\begin{array}{c}\text { Resistant } \\
n(\%)\end{array}$ & $\begin{array}{c}\text { Total tested } \\
n(\%)\end{array}$ & $\begin{array}{c}\text { Resistant } \\
n(\%)\end{array}$ & $\begin{array}{c}\text { Total tested } \\
n(\%)\end{array}$ & $\begin{array}{c}\text { Resistant } \\
n(\%)\end{array}$ \\
\hline \multicolumn{7}{|l|}{ Group 1} \\
\hline Ethambutol & 250 (96.9) & $141(56.4)$ & $88(98.9$ & $52(59.1)$ & $33(100)$ & $27(81.8)$ \\
\hline Pyrazinamide & $98(38.0)$ & $44(44.9)$ & $56(62.9)$ & $44(78.5)$ & $18(54.5)$ & $17(94.4)$ \\
\hline Streptomycin & $247(95.7)$ & $218(88.3)$ & $86(96.6)$ & $83(96.5)$ & $31(93.9)$ & $30(96.8)$ \\
\hline \multicolumn{7}{|l|}{ Group 2} \\
\hline Any SLI & $234(90.7)$ & NA & $89(100)$ & $60(67.4)$ & $33(100)$ & $33(100)$ \\
\hline Amikacin & $97(37.6)$ & NA & $56(62.9)$ & $26(46.4)$ & $27(81.8)$ & $16(59.3)$ \\
\hline Capreomycin & $171(66.3)$ & NA & $67(75.3)$ & $26(38.8)$ & $28(84.8$ & $19(67.9)$ \\
\hline Kanamycin & $189(73.3)$ & NA & $72(80.9)$ & $44(61.1)$ & $27(81.8)$ & $24(88.9)$ \\
\hline \multicolumn{7}{|l|}{ Group 3} \\
\hline Any FQ & $230(89.1)$ & NA & $89(100)$ & $29(32.6)$ & $33(100)$ & $33(100)$ \\
\hline Levofloxacin & $17(6.6)$ & NA & $10(11.2)$ & $3(30.0)$ & $5(15.2)$ & $1(20.0)$ \\
\hline Moxifloxacin & $39(15.1)$ & NA & $23(25.8)$ & $8(34.8)$ & $11(33.3)$ & $9(81.8)$ \\
\hline Ofloxacin & $209(81.0)$ & NA & $82(92.1)$ & $23(28.0)$ & $33(100)$ & $33(100)$ \\
\hline \multicolumn{7}{|l|}{ Group 4} \\
\hline Cycloserin/terizidon & $129(50.0)$ & $6(4.7)$ & $65(73.0)$ & $6(9.2)$ & $25(75.8$ & $11(44.0$ \\
\hline Ethionamide/prothionamide & $234(90.7)$ & $65(27.8)$ & $87(97.8)$ & $38(42.7)$ & $33(100)$ & $16(48.5)$ \\
\hline PAS & $193(74.8)$ & $6(3.1)$ & $69(77.5)$ & $7(10.1)$ & $29(87.9)$ & $9(31.0)$ \\
\hline \multicolumn{7}{|l|}{ Group 5} \\
\hline Amoxicillin/clavulanic acid & 0 & NA & 0 & NA & 0 & NA \\
\hline Clarithromycin & $12(4.7)$ & $3(25.0)$ & $2(2.2)$ & 0 & $3(9.1)$ & 0.0 \\
\hline Imipenem & 0 & NA & 0 & NA & 0 & NA \\
\hline Linezolid & 40 (15.5) & 0 & 21 (23.6) & 0 & $8(24.2)$ & $2(25.0)$ \\
\hline Meropenem & 0 & NA & $1(1.1)$ & $1(100)$ & 0 & NA \\
\hline Clofazimine & 0 & NA & 0 & NA & 0 & NA \\
\hline
\end{tabular}

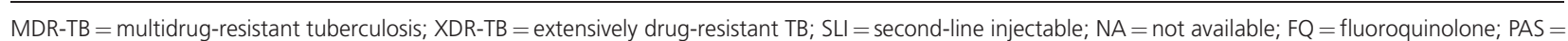
para-aminosalicylic acid.

\section{METHODS}

Patients who provided informed consent and were started on treatment for a new episode of cultureconfirmed MDR-TB (resistance to at least RMP and INH) were eligible for enrolment, as described elsewhere. ${ }^{3}$ All consecutive MDR-TB patients who gave consent at each site during the study period were included in the cohort. Ethics approval was obtained from the University of Lübeck, Lübeck, Germany, and subsequently at other participating sites. An electronic case record form (www.openclinica.com) was used for data collection.

Patients were classified as having MDR-TB, preXDR-TB or XDR-TB based on DST results for the culture-positive sputum specimen obtained closest to the start of appropriate treatment for this resistance pattern. All laboratories at the study sites were qualitycontrolled by the WHO Supranational Reference Laboratory Network. Phenotypic testing was performed at all sites using liquid culture, with the exception of Romania. The frequency of DST and the proportion of strains classified as resistant are reported for individual drugs and specific groups of drugs.

Ordinal logistic regression was performed to assess variables associated with increased drug resistance, in which the outcome variable was ordered as MDR-, pre-XDR- and XDR-TB. All included variables were dichotomised. To align with earlier analyses in the current cohort and other studies, age was dichotomised at 45 years. Variables were included in a multivariable model if $P<0.10$ in the univariable model. Odds ratios (ORs) with their associated $95 \%$ confidence intervals (CIs) were calculated. The level of statistical significance was set at $5 \%$.

\section{RESULTS}

The cohort included 380 patients with at least RMPand INH-resistant M. tuberculosis. Bacillary strains from $356(93.7 \%)$ patients were tested for at least one SLI, and $352(92.6 \%)$ for an FQ. A total of $33(8.7 \%)$ patients were classified as XDR-TB based on the DST results, and $89(23.4 \%)$ as pre-XDR-TB.

Table 1 shows low DST capacity for later-generation FQs (levofloxacin and moxifloxacin) and linezolid at the participating centres in Europe. Bacilli from patients with pre-XDR-TB showed $>30 \%$ resistance to any FQ and almost $70 \%$ to any SLI. Respectively $>90 \%$ and $>80 \%$ of the tested XDR-TB M. tuberculosis strains showed phenotypic resistance to pyrazinamide (PZA) and ethambutol. Additional resistance to prothionamide/ethionamide was high in bacilli from both pre-XDR- $(43 \%)$ and XDR-TB patients $(49 \%)$. DST against Group 5 drugs was rarely performed.

Previous anti-tuberculosis treatment and age $<45$ years were independent risk factors for MDR-TB in this cohort. ${ }^{5,6}$ Table 2 shows the results of the 
Table 2 Results of a multinomial logistic regression analysis with possible risk factors for increase in levels of M. tuberculosis drug resistance

\begin{tabular}{|c|c|c|c|c|c|}
\hline \multirow[b]{2}{*}{ Variable } & \multicolumn{3}{|c|}{ Predicted probabilities } & \multirow[b]{2}{*}{ OR $(95 \% \mathrm{Cl})$} & \multirow[b]{2}{*}{$P$ value } \\
\hline & MDR-TB & Pre-XDR-TB & XDR-TB & & \\
\hline \multicolumn{6}{|l|}{ Sex } \\
\hline Male & 67.2 & 26.0 & 6.8 & & \\
\hline Female & 69.0 & 24.7 & 6.3 & $0.92(0.59-1.43)$ & 0.720 \\
\hline \multicolumn{6}{|l|}{ Age $<45$ years } \\
\hline No & 68.3 & 25.1 & 6.6 & & \\
\hline Yes & 67.8 & 25.5 & 6.7 & $1.02(0.64-1.64)$ & 0.921 \\
\hline \multicolumn{6}{|l|}{ Previous TB } \\
\hline No/unknown & 67.2 & 26.0 & 6.8 & & \\
\hline Yes & 68.6 & 25.0 & 6.4 & $0.94(0.61-1.44)$ & 0.773 \\
\hline \multicolumn{6}{|l|}{ Unemployment } \\
\hline No/unknown & 69.2 & 24.6 & 6.2 & & \\
\hline Yes & 65.8 & 27.0 & 7.2 & $1.17(0.75-1.80)$ & 0.491 \\
\hline \multicolumn{6}{|c|}{ Previous imprisonment } \\
\hline No/unknown & 68.0 & 25.5 & 6.6 & & \\
\hline Yes & 66.8 & 26.3 & 6.9 & $1.06(0.48-2.31)$ & 0.887 \\
\hline \multicolumn{6}{|c|}{ Current or previous homelessness } \\
\hline No/unknown & 68.1 & 25.4 & 6.5 & & \\
\hline Yes & 63.2 & 28.8 & 8.0 & $1.24(0.45-3.42)$ & 0.673 \\
\hline \multicolumn{6}{|c|}{ Intravenous drug user } \\
\hline No/unknown & 67.7 & 25.7 & 6.6 & & \\
\hline Yes & 71.3 & 23.1 & 5.7 & $0.84(0.34-2.07)$ & 0.708 \\
\hline \multicolumn{6}{|l|}{ HIV-infected } \\
\hline No/unknown & 68.9 & 24.8 & 6.2 & & \\
\hline Yes & 53.7 & 35.1 & 11.3 & $1.91(0.88-4.16)$ & 0.103 \\
\hline \multicolumn{6}{|c|}{ Hepatitis B-infected } \\
\hline No/unknown & 68.5 & 25.1 & 6.4 & & \\
\hline Yes & 55.3 & 34.0 & 10.7 & $1.76(0.70-4.45)$ & 0.235 \\
\hline \multicolumn{6}{|c|}{ Hepatitis C-infected } \\
\hline No/unknown & 68.5 & 25.1 & 6.4 & & \\
\hline Yes & 55.3 & 34.0 & 10.7 & $1.76(0.69-4.45)$ & 0.235 \\
\hline \multicolumn{6}{|l|}{ Diabetes } \\
\hline No/unknown & 68.7 & 25.0 & 6.3 & & \\
\hline Yes & 45.8 & 39.4 & 14.8 & $2.59(0.90-7.45)$ & 0.077 \\
\hline
\end{tabular}

$\mathrm{OR}=$ odds ratio; $\mathrm{Cl}=$ confidence interval; $\mathrm{MDR}-\mathrm{TB}=$ multidrug-resistant $\mathrm{TB} ; \mathrm{XDR}-\mathrm{TB}=$ extensively drug-resistant TB; TB = tuberculosis; HIV = human immunodeficiency virus.

multinomial logistic regression analysis. None of the risk factors were seen to have a predictive value with regard to an increased level of drug resistance.

\section{DISCUSSION}

In this European cohort of patients infected with $M$. tuberculosis strains and resistance to at least RMP and INH, almost one quarter of infecting strains showed additional resistance to either an SLI or an FQ at the start of treatment (pre-XDR-TB), while $8.7 \%$ of the MDR-TB strains fulfilled our definition for XDR-TB. PZA resistance testing was infrequently performed in high proportions of resistance in $M$. tuberculosis strains (44.9\% for MDR-, $78.5 \%$ for pre-XDR- and $94.4 \%$ for XDR-TB). These findings challenge the current WHO recommendation, issued in 2011, of treating all MDR-TB patients with PZA, and limit the possible use of this drug in new regimens currently under development. ${ }^{7,8}$

The importance of drug resistance in addition to RMP and INH resistance in relation to treatment success was recently highlighted in an analysis of 9153 MDR-TB patients. The study demonstrated the association of in vitro susceptibility to first- and second-line drugs with higher odds of treatment success. ${ }^{9}$ Additional in vitro resistance, as observed in this European cohort, is thus likely to increase the frequency of treatment failure. This finding is complicated by the fact that the risk of acquired drug resistance during anti-tuberculosis treatment increases substantially with increasing resistance to other drugs in the regimen. ${ }^{10}$

Results from this observational cohort study suggest that wider use of DST might reveal high levels of second-line anti-tuberculosis drug resistance in Europe, including a higher frequency of XDR-TB. The combination of the low frequency of DST against second-line drugs, and the finding of high resistance levels to those drugs when tested, might explain the recently reported low treatment success rate for MDR-TB in Europe. ${ }^{4}$ In agreement with the results from the Preserving Effective TB Treatment Study (PETTS), we did not find any association between 
selected risk factors and increasing levels of drug resistance. ${ }^{10}$ Individual risk factors present for MDRTB could therefore well be indicative of underlying pre-XDR- or XDR-TB, thus necessitating DST for second-line drugs.

Our study has several limitations. Data were derived from an international multicentre observational cohort study and not from routine drug resistance surveillance. Although hospitals specialising in the care of MDR-/XDR-TB patients from 14 of $28 \mathrm{EU}$ and 2 non-EU countries participated in the study, the data may not be generalisable to all of Europe. Selection bias due to the inclusion of only MDR-TB cases who were severely ill is thought to be limited, given the consecutive sampling approach and the fact that MDR-/XDR-TB was treated in only a few specialist centres in each country. For greater representativeness of the data, we also performed weighted analyses stratified by incidence based on the sampling fraction and the expected number of notified MDR-TB patients in the countries from which patients were recruited. These results suggest that, at the very least, frequencies of resistance against second-line drugs might even have been underestimated in our cohort (data not shown).

In conclusion, we identified a low frequency of DST coverage for later-generation FQ and WHO Class 5 anti-tuberculosis drugs, and a high frequency of $M$. tuberculosis strains resistant to second-line anti-tuberculosis drugs in addition to RMP and INH. Our findings contribute to a better understanding of the poor treatment outcomes in MDR-TB patients in Europe,${ }^{4}$ and argue against the use of standardised drug regimens for MDR-TB treatment in this region. Our results indicate the urgent need to scale up molecular (genotypic) and phenotypic second-line DST in Europe to obtain much needed results before treatment start and to facilitate the use of appropriate and effective regimens for patients with drug-resistant TB.

\section{Acknowledgements}

The authors thank B Prins (Amsterdam Institute for Global Health and Development, Amsterdam, The Netherlands), N Smitsman (Research Center Borstel, Borstel, Germany) and C Ehlers (Tuberculosis Network European Trials [TBNET]) for technical assistance.

Other TBNET contributors: S Alexandru, I Cernenco, A Ciobanu, A Donica, (Institute of Phthisiopneumology, Chisinau, Republic of Moldova); J Cayla, L Fina (Agencia de Salud Publica de Barcelona, Barcelona); M L de Souza Galvao, J Maldonado (Hospital Universitari Vall d'Hebron, Investigació i Recerca en Atenció Primària Jordi Gol, Barcelona, Spain); K Avsar (Asklepios Klinik Gauting, Gauting, Germany); D Bang (Statens Serum Institut, Copenhagen), A B Andersen (Herlev Hospital, Herlev, Denmark); R Barbuta, V Dubceac (Balti Municipal Hospital, Balti, Republic of Moldova); G Bothamley (Homerton University Hospital, London, United Kingdom); V Crudu (National TB Reference Laboratory, Institute of Phthisiopneumology, Chisinau,
Republic of Moldova); M Davilovits (Tartu University Lung Hospital, Tartu, Estonia); A Atunes (Vila Nova Gaia/Espinho Medical School, Vila Nova Gaia, Porto University, Porto, Portugal); W de Lange (University Medical Centre Groningen, Groningen, The Netherlands); V Leimane, L Rusmane (Riga East University Hospital, Riga, Latvia); S de Lorenzo (Azienda Ospedaliera di Valtellina e Valchiavenna E Morelli Hospital, Reference Hospital for MDR and HIV-TB, Sondalo, Italy); F Cuppen, I de Guchtenaire, C Magis-Escurra (Radboud University Medical Centre, Nijmegen/Groesbeek, The Netherlands); A-M McLaughlin (St James's Hospital, Dublin, Ireland); R Meesters, M te Pas, B Prins (Department of Global Health, Academic Medical Center, University of Amsterdam, Amsterdam Institute for Global Health and Development, Amsterdam, The Netherlands); R Mütterlein (Hospital Parsberg, Parsberg, Germany); J Kotrbova, V Polcová, M Vasakova (Thomayer University Hospital, Prague, Czech Republic); E Pontali (Galliera Hospital, Genoa, Italy); R Rumetshofer, M Rowhani (Otto Wagner Hospital, Vienna, Austria); A Skrahina, V Avchinko, D Katovich, D Klimuk, V Lobik, Z Rohaya, A Shirochyn, V Solodovnikova (Republican Research and Practical Centre for Pulmonology and Tuberculosis, Minsk, Belarus); N Smitsman (Research Centre Borstel, Borstel, Germany); C Popa, D Gainaru, E Ibraim, M Tigau (Marius-NastaInstitut, Bucharest, Romania).

This work was supported by the European Commission Seventh Framework Programme (FP7/2007-2013) under grant agreement FP7-223681. CL is funded by the German Center for Infection Research.

Conflicts of interest: none declared.

\section{References}

1 World Health Organization. Global strategy and targets for tuberculosis prevention, care and control after 2015. EB 134/ 12. Geneva, Switzerland: WHO, 2014.

2 World Health Organization. Definitions and reporting framework for tuberculosis. WHO/HTM/TB/2013.2. Geneva, Switzerland: WHO, 2013.

3 Falzon D, Gandhi N, Migliori G B, et al. Resistance to fluoroquinolones and second-line injectable drugs: impact on multidrug-resistant TB outcomes. Eur Respir J 2013; 42: 156168.

4 World Health Organization \& European Centers for Diseases Prevention and Control. Tuberculosis Surveillance and monitoring in Europe, 2014. Stockholm, Sweden: ECDC, 2014.

5 Günther G, van Leth F, Alexandru S, et al. Multidrug-resistant tuberculosis in Europe, 2010-2011. Emerg Infect Dis 2015; 21: 409-416.

6 Lange C, Abubakar I, Alffenaar J W, et al. Management of patients with multidrug-resistant/extensively drug-resistant tuberculosis in Europe: a TBNET consensus statement. Eur Respir J 2014; 44: 23-63.

7 World Health Organization. Guidelines for the programmatic management of drug-resistant tuberculosis: update 2011. WHO/HTM/TB/2011.6. Geneva, Switzerland: WHO, 2011.

8 Diacon A H, Dawson R, von Groote-Bidlingmaier F, et al. 14day bactericidal activity of PA-824, bedaquiline, pyrazinamide, and moxifloxacin combinations: a randomised trial. Lancet 2012; 380: 986-993

9 Bastos M L, Hussain H, Weyer K, et al. Treatment outcomes of patients with multidrug-resistant and extensively drug-resistant tuberculosis according to drug susceptibility testing to first- and second-line drugs: an individual patient data meta-analysis. Clin Infect Dis 2014; 59: 1364-1374

10 Cegielski J P, Dalton T, Yagui M, et al. Extensive drug resistance acquired during treatment of multidrug-resistant tuberculosis. Clin Infect Dis 2014; 59: 1049-1063. 
L'émergence de la tuberculose (TB) pharmacorésistante est un défi vis-à-vis de la lutte contre la TB en Europe. Nous avons évalué les tests de sensitibilité aux médicaments de deuxième ligne de Mycobacterium tuberculosis provenant de patients atteints de TB multirésistante (TB-MDR), pré-ultrarésistante (TB préXDR) et TB-XDR dans 23 sites TBNET dans 16 pays d'Europe. Plus de 30\% des bacilles de patients atteints de TB pré-XDR ont démontré une résistance à toutes les fluoroquinolones et à presque $70 \%$ de tous les médicaments de deuxième ligne injectables. Plus de $90 \%$ et plus de $80 \%$ respectivement des souches TBXDR testées ont démontré une pharmacorésistance phénotypique vis-à-vis du pyrazinamide et de l'éthambutol. La pharmacorésistance au prothionamide/éthionamide a été élevée pour les bacilles de patients atteints de TB pré-XDR (43\%) et TB-XDR (49\%).

RE S U M E N

La aparición de tuberculosis (TB) farmacorresistente representa un peligro en el control de la TB en Europa. En el presente estudio se evaluaron dos pruebas de sensibilidad de Mycobacterium tuberculosis a los medicamentos de segunda línea, en pacientes con TB multidrogorresistente (TB-MDR), pre-extremadamente drogorresistente (TB pre-XDR) y TB-XDR provenientes de 23 centros del grupo TBNET en 16 países europeos. Más del 30\% de los bacilos provenientes de los pacientes con TB pre-XDR exhibió resistencia a todas las fluoroquinolonas y cerca del $70 \%$ fue resistente a todos los medicamentos inyectables de segunda línea. De las cepas causantes de TB-XDR estudiadas, más del $\mathbf{9 0 \%}$ presentó resistencia a pirazinamida y más del $\mathbf{8 0 \%}$ a etambutol. La farmacorresistencia a protionamida y etionamida fue alta en los bacilos de pacientes con TB pre-XDR (43\%) y TB-XDR (49\%). 